\section{§1. Development of Anti-corrosion Coating on Low Activation Materials against Fluoridation and Oxidation in Flibe Blanket Environment}

Nagasaka, T., Kondo, M., Muroga, T., Sagara, A., Motojima, O.,

Tsutsumi, T., Oishi, T. (Shinto Industrial Co., LTD)

Liquid breeder blanket is promising for DEMO and commercial fusion reactors. Flibe molten salt $(\mathrm{BeF} 2+\mathrm{LiF})$ is a very attractive liquid breeder material. Corrosion of structural materials by HF (TF from tritium breeding) is one of critical issues for Flibe blanket system. In addition, oxidation has been identified as a potential corrosion process in Flibe with moisture impurity. In the present study, tungsten (W) coating was fabricated by vacuum plasma spray (VPS) process. Chromium coating was fabricated by chromizing process. The present study seeks to evaluate feasibility of the coatings for fusion low activation materials, to characterize microstructure, and to examine chemical stability of coatings by fluoridation and oxidation tests.

The low-activation materials used were 1-inch-thick plates of JLF-1 JOYO-II heat (Fe- 9.00Cr- 1.98W- 0.090C$0.015 \mathrm{~N}-0.20 \mathrm{~V}-0.083 \mathrm{Ta}$ ) and NIFS-HEAT-2 (NH2, V4.02Cr- 3.98Ti- $0.0069 \mathrm{C}-0.0122 \mathrm{~N}-0.0148 \mathrm{O}$ ). The W powder was melted and sprayed on the substrate by a plasma jet of argon and hydrogen mixture in a vacuum chamber. The resulting thickness of the $\mathrm{W}$ coatings was about $0.4 \sim 0.8 \mathrm{~mm}$. Cromizing was performed by using chemical vapor deposition with $\mathrm{NH}_{4} \mathrm{Cl}$ and pure $\mathrm{Cr}$ powders. The coupon specimens were exposed to $\mathrm{H}_{2} \mathrm{O}-47 \% \mathrm{HF}$ solution at room temperature (RT) for $2 \mathrm{~min}$ and $\mathrm{He}-$ $1 \% \mathrm{HF}-0.06 \mathrm{H}_{2} \mathrm{O}$ gas mixture at $823 \mathrm{~K}$ for $2.5 \mathrm{hr}$.

Figs. 1 and 2 present a cross section of the VPS-W coatings and $\mathrm{Cr}$ coatings by chromizing, rspectively. About $80 \mu \mathrm{m}$-thick coating was successfully obtained for JLF-1, however mean coating thickness for $\mathrm{NH} 2$ was estimated as less than $5 \mu \mathrm{m}$. Easily peeling layer considered as oxide was formed, instead, on the NH2 substrate. Since the mean coating thickness was too small for $\mathrm{NH} 2$, the chromized $\mathrm{NH} 2$ was not transferred to the subsequent corrosion tests.

Fig. 3 plots the weight change after the corrosion tests. JLF-1 and NH2, exhibited similar weight losses each other. In the $\mathrm{H}_{2} \mathrm{O}-\mathrm{HF}$ solution tests, pure $\mathrm{Cr}$ and $\mathrm{W}$ exhibited a $1 / 30$ to $1 / 50$ weight loss compared with the low-activation materials. VPS-W specimens machined from the VPS-W part showed $1 / 3$ to $1 / 5$ weight loss compared with the low activation materials, however it is 10 times larger than that of pure W. Cromized JLF-1 (Cr-JLF-1) indicated similar weight loss to pure $\mathrm{Cr}$. In the $\mathrm{He}-\mathrm{HF}-\mathrm{H}_{2} \mathrm{O}$ gas corrosion tests, the VPS-W showed weight loss, while the others resulted in weigh gain. The weight gain of $\mathrm{NH} 2$ was 10 times greater than that of JLF-1. The weight gain of Cr-JLF-1 was similar to that of JLF-1.

According to XPS analyses, both the VPS-W and Cr-JLF-1 suppressed fluoride formation compared with JLF-1 or NH2. It is well known that V alloy is easily oxidized at elevated temperature, as the large weight gain and were indicated for the gas condition test in Fig. 3. Suppression of oxide formation is especially expected for

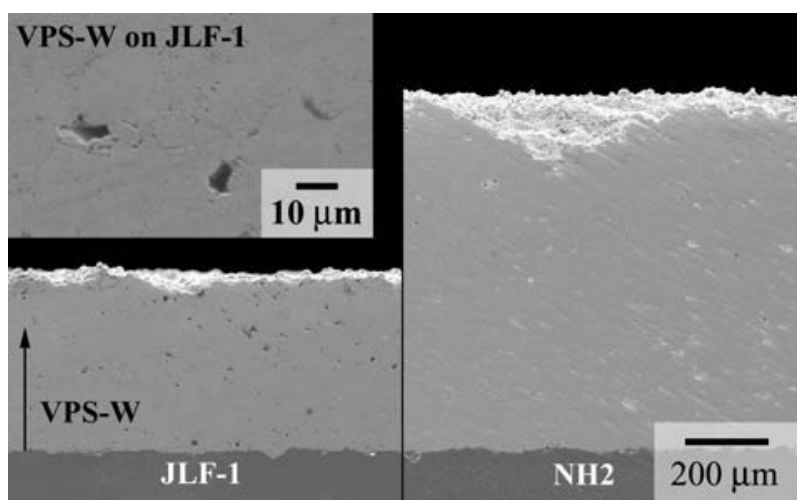

Fig. 1 SEM images of the cross section of $\mathrm{W}$ coating.

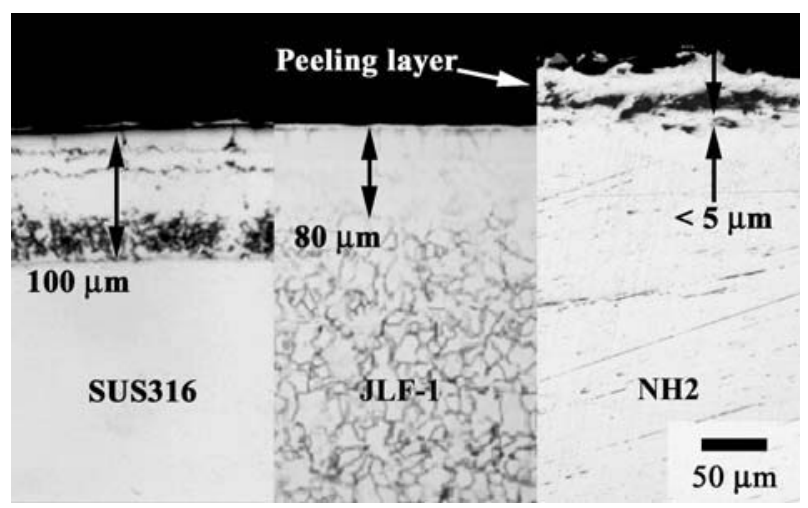

Fig. $2 \mathrm{OM}$ images of the cross section of $\mathrm{Cr}$ coating.

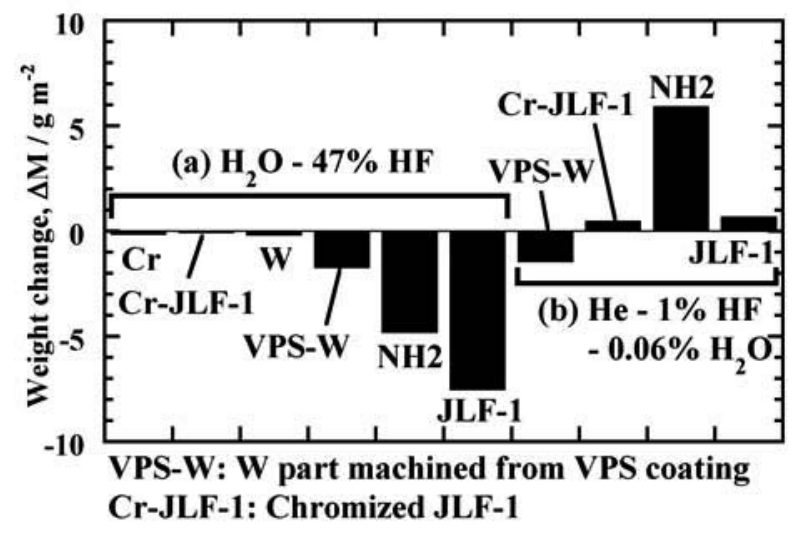

Fig. 3 Weight change after corrosion tests.

$\mathrm{NH} 2$ by $\mathrm{W}$ coating.

$\mathrm{Cr}$ coating decreased fluoridation and oxidation in $\mathrm{H}_{2} \mathrm{O}-\mathrm{HF}$ solution condition, however much $\mathrm{Cr}_{2} \mathrm{O}_{3}$ was produced in $\mathrm{He}-\mathrm{HF}-\mathrm{H}_{2} \mathrm{O}$ gas and may be dissolved into Flibe. Protective and thin $\mathrm{Cr}_{2} \mathrm{O}_{3}$ layer common in high $\mathrm{Cr}$ stainless steel was not formed in the present study. Systematic research with various oxygen potential, for example, by control of moisture level in the corrosion gas, is expected to produce protective layer. It must be, however, noted that $\mathrm{Cr}$ concentration decreases with the depth from the coating surface, and that corrosion behavior will be changed once the surface is removed. Effect of concentration of $\mathrm{Cr}$ has to be investigated further.

This study was promoted by NIFS budget code NIFS08UCFF002 and NIFS08UCFF003. 